\title{
A novel vaccine for cervical cancer: quadrivalent human papillomavirus (types 6, II, 16 and 18) recombinant vaccine $\left(\right.$ Gardasil $\left.^{\circledR}\right)$
}

\author{
Vandana A Govan \\ Division of Medical Virology, \\ Department of Clinical Laboratory \\ Sciences and Institute of Infectious \\ Diseases and Molecular Medicine, \\ Faculty of Health Sciences, University \\ of Cape Town, Observatory, Cape \\ Town, South Africa
}

\begin{abstract}
Human papillomaviruses (HPVs) are one of the most common sexually transmitted infections and remains a public health problem worldwide. There is strong evidence that HPV causes cervical, vulva and vaginal cancers, genital warts and recurrent respiratory papillomatosis. The current treatments for HPV-induced infections are ineffective and recurrence is commonplace. Therefore, to reduce the burden of HPV-induced infections, several studies have investigated the efficacy of different prophylactic vaccines in clinical human trials directed against HPV types $6,11,16$, or 18. Notably, these HPV types contribute to a significant proportion of disease worldwide. This review will focus on the published results of Merck \& Co's prophylactic quadrivalent recombinant vaccine targeting HPV types 6, 11, 16, and 18 (referred to as

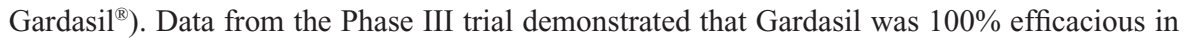
preventing precancerous lesions of the cervix, vulva, and vagina and effective against genital warts. Due to the success of these human clinical trials, the FDA approved the registration of Gardasil on the 8 June 2006. In addition, since Gardasil has been efficacious for 5 years post vaccination, the longest evaluation of an HPV vaccine, it is expected to reduce the incidence of these type specific HPV-induced diseases in the future.
\end{abstract}

Keywords: Gardasil, HPV, prophylactic vaccine, cervical disease

\section{Introduction}

Papillomaviruses (PVs) are DNA tumor viruses and infect squamous or mucosal epithelia (Stanely 2003). To date, there are over 100 different human PV (HPV) genotypes that have been fully sequenced and can be divided into low-risk, nononcogenic, or high-risk oncogenic types (de Villiers et al 2004; Bernard 2005) by their viral ability to cause malignant disease (Munoz et al 2003) (Table 1). The predominant low-risk types are HPV 6 and 11 and cause $90 \%$ of genital warts (condyloma acuminata) while HPV 16 and 18 are the most prevalent high-risk types, causing 70\% of cervical cancer and cervical intra-epithelial neoplasia (CIN) (de Villiers et al 2004) and are considered to be the most destructive oncogenic viruses worldwide. Globally, the incidence and mortality rates of new cases, caused by HPV-related cervical cancer were estimated to be approximately 500,000 in 2002 (Ferlay et al 2004). In addition, it is estimated that sexually active men and women have a 50\% lifetime risk of HPV infection (WHO 2004).

Interestingly, although the prevalence of HPV DNA among most sexually active women in the general population is high, these infections are generally transient and infected individuals are able to eliminate the virus without intervention and do not develop cancer (Koutsky 1997). Thus an effective host immune response and the genetic make-up of the individual may be an important determinant for the persistence and progression of HPV induced cervical cancer (Magnusson and Gyllensten 2000). 
Table I The major high- and low-risk HPV types

\begin{tabular}{ll}
\hline Classification & HPV types \\
\hline High-risk types & I6, I8, 3I, 33, 35, 39, 45, 5I, 52, 56, 58, 59, 68, 73, 82 \\
Low-risk types & $6,1 \mathrm{I}, 40,42,43,44,54,6 \mathrm{I}, 70,72,8 \mathrm{I}, \mathrm{CP} 6 \mathrm{I}$ 108 \\
Potentially high-risk & $26,53,66$ \\
\hline
\end{tabular}

Consequently, several studies have investigated genetic host factors and immune responses, to describe the association between genital HPV infection and cervical cancer (Stanczuk et al 2001; Deshpande et al 2005; Govan et al 2005). Although these investigations have not elucidated the role of a few genetic host factors for the development of cervical cancer these studies emphasize the possible variability of genetic host factors and ethnic disparity in diverse population groups and should thus, not be viewed in isolation as other confounding factors may contribute to the progression of disease (Govan et al 2003).

\section{Current therapies for HPV-related disease}

Up until now the current approaches for the treatment and control of HPV-related infections have been variable. Although condoms may afford some protection, infection by HPV types may still occur via the unprotected areas of the genital skin (Burchell et al 2006). In addition, despite the widely adopted and effective cervical cytology screening test, Papanicolaou (Pap) smear, the incidence of new HPVinduced infections remains a global public health problem, particularly in developing countries where cervical cancer is the most common cancer among women (WHO 2004). The main contributing factors that are responsible for this health problem in several countries is due to the lack of established and stringent routine screening programs and even in developed nations the disadvantaged minorities may not have access to cervical cancer screening (Roden and Wu 2006). Furthermore, the accepted treatments for HPV-related disease are limited, uncomfortable, invasive, costly and inefficient with a high relapse rate (Robinson 2001). Therefore, a preventative treatment approach such as the development of a prophylactic vaccine would be the most cost effective means to reduce the incidence of HPV-related infections.

\section{Biology of PV}

When selecting vaccine targets an understanding of the molecular pathogenesis of PV-associated infections is central, as PVs are able to evade the host immune system in the early stages of carcinogenesis. The lifecycles of PVs are linked to the differentiation stages of the host epithelial cells, and replication is restricted exclusively to the stratified squamous epithelium (Frazer 2004). PVs are small, nonenveloped viruses containing a $8 \mathrm{~kb}$ double-stranded closed circular DNA genome, encoding six early proteins (E1, E2, E4, E5, E6 and E7), two late proteins (L1 and L2) and a non-coding regulatory region, the long-control region (LCR) (zur Hausen 2000). The general organization of the HPV genome is shown in Figure 1. The early genes contribute to transformation and viral replication, the late genes provide capsid proteins and the LCR contains the origin of replication (zur Hausen 2000).

\section{Rationale for a preventative vaccine}

As PVs are host and tissue specific, several animal PV models have been developed and have provided significant information for vaccine development. In particular, preclinical studies using the cottontail rabbit papillomavirus (CRPV) in rabbits, bovine papillomavirus (BPV) in cattle and canine oral papillomavirus (COPV) in dogs have successfully provided a better understanding of the molecular mechanism that regulate normal cell growth, steps involved in cancerous cell changes (Frazer 2004) and have tested the potential of different delivery systems (Breitburd et al 1995; Jansen et al 1995; Brandsma et al 2004; Govan et al 2006).

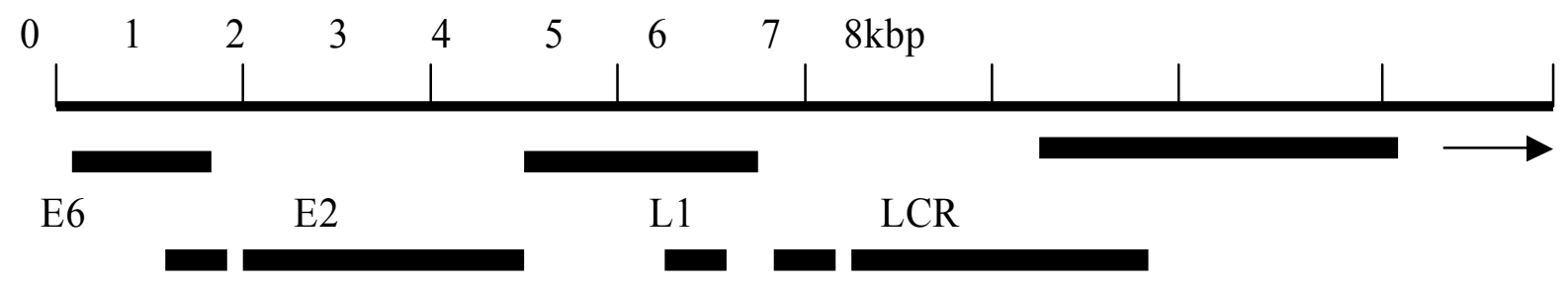

$\begin{array}{lllll}\text { E7 } & \text { E1 } & \text { E4 } & \text { E5 } & \text { L2 }\end{array}$

Figure I A linearized general organization of the HPV I6 genome (7.905 base pairs) showing the long control region (LCR), the early (E), and late (L) genes. 
It has been shown that the expression of PV L1 genes in vitro results in the assembly of virus-like particles (VLPs) and induces high titers of virus-neutralizing serum antibodies when administered as an immunogen (Hines et al 1994; Christensen et al 1994). Although VLPs are morphologically and antigenically almost indistinguishable from the native HPV virion, they are non-infectious, lack viral DNA, and most importantly they are highly immunogenic and afford protection from papillomavirus challenge. Due to the encouraging animal studies, efforts to produce a vaccine against $\mathrm{HPV}$-induced infections were centered on the major capsid protein, L1 VLPs and were translated into human phase I clinical trials.

\section{Efficacy trials}

In a placebo-controlled human clinical trial, women who were HPV 16 negative, at the time of vaccination, were protected 17.4 months post HPV 16 L1 VLP vaccination from the development of CIN (Koutsky et al 2002). This yeast produced HPV 16 VLP vaccine was $100 \%$ efficacious in the prevention of HPV16-induced infection. Consequently, following on the successful human clinical trials, two pharmaceuticals companies, GlaxoSmithKline (GSK) and Merck \& Co developed bivalent and quadrivalent HPV-VLP L1 vaccines respectively. GSK assessed the efficacy of a bivalent HPV16/18 VLP vaccine. The L1 protein of each type was expressed via a recombinant baculovirus vector where the resulting VLPs were combined to produce the vaccine, Cervarix ${ }^{\mathrm{TM}}$. Cervarix has been shown to be efficacious through 4.5 years, highly immnuonogenic and safe, and there is evidence of crossprotection against incident infection with HPV types 31 and 45 (Harper et al 2006). The quadrivalent vaccine by Merck and Co was prepared in a yeast system and the expressed L1 protein of each type was combined to generate Gardasil $^{\circledR}$. To date, Gardasil has been shown to be highly effective trough 5 years in the prevention of HPV induced disease (Villa et al 2006). The description and composition of Cervarix and Gardasil are tabulated in Table 2. This review will focus only on the results generated from the clinical trials of Gardasil (manufactured by Merck and Co, Inc, Whitehouse Station, New Jersey). The efficacy data of the randomized, placebo-controlled efficacy trials of the HPV L1 VLP vaccines are summarized in Table 3 and the important recommendations stated by the Advisory Committee on Immunization Practices (ACIP) are tabulated in Table 4.

\section{Drawbacks of the quadrivalent vaccine}

\section{Type specificity}

It has been shown in pre-clinical animal challenge models (Breitburd et al 1995) and clinical human trials (Koutsky et al 2002) that immunization with a type-specific PV L1 VLP will elicit protection only to the same homologous PV type. In addition, it was reported that in a clinical human trial, women who were vaccinated against HPV 16 L1 VLP, a number of women developed CIN lesions that were induced by other HPV types other than HPV 16 (Koutsky et al 2002). However, it should be noted that evidence of cross-protection has been shown in Cervarix against infection with HPV 31 and HPV 45. Nevertheless, it is estimated that the preventative quadrivalent vaccine will not provide protection against the almost $30 \%$ of cervical

Table 2 Description and composition of the bivalent and quadrivalent HPV-LI vaccines in human clinical trials

\begin{tabular}{|c|c|c|}
\hline & Gardasil $^{\circledR}$ & Cervarix $^{\mathrm{TM}}$ \\
\hline I. Company & Merck \& Co & GlaxoSmithKline \\
\hline 2. Vaccine formulation & VLP derived from HPV $6,11,16$ and 18 & VLPs derived from HPV 16 and 18 \\
\hline 3. Composition & Produced in a yeast system & Produced in an insect-cell system \\
\hline 4. Route of administration & Intramuscular & Intramuscular \\
\hline 5. Dose schedule & three-dose regime 0,2 , and 6 months & three-dose regime 0,1 , and 6 months \\
\hline \multirow[t]{3}{*}{ 6. Dosages } & $0.5 \mathrm{~mL}$ (containing $20 \mu \mathrm{g} \mathrm{HPV6}$ & $0.5 \mathrm{~mL}$ (containing $20 \mu \mathrm{g} \mathrm{HPVI} 6$ and \\
\hline & $40 \mu \mathrm{g}$ HPVII, $40 \mu \mathrm{g}$ HPVI 6 and $20 \mu \mathrm{g}$ & $20 \mu g$ HPVI 8 \\
\hline & HPVI8VLP & \\
\hline \multirow[t]{2}{*}{ 7. Adjuvant } & $225 \mu \mathrm{g}$ of aluminium hydroxyphosphate & $50 \mu \mathrm{g}$ of aluminium hydroxide with $50 \mu \mathrm{g}$ \\
\hline & sulphate (alum) & of ASO4 \\
\hline 8. Current analysis of vaccine & Safe, well tolerated and $100 \%$ efficacious & Safe, well tolerated and $100 \%$ efficacious \\
\hline 9. Sustained efficacy & Effective through $5 \mathrm{yrs}^{\mathrm{a}}$ & Effective through $4.5 \mathrm{yrs}^{\mathrm{b}}$ \\
\hline 10. Licensed for public use & $>60$ countries & Australia (women $\leq 45$ yrs) \\
\hline
\end{tabular}

ailla et al (2006)

bHarper et al (2006). 
Table 3 Summary of the randomized, human placebo-controlled efficacy trials of Gardasi ${ }^{\circledR}$

\begin{tabular}{lllll}
\hline VLP vaccine & $\begin{array}{l}\text { Vaccine/placebo } \\
\text { group }\end{array}$ & Vaccine schedule & $\begin{array}{l}\text { Duration of trial } \\
\text { (months) }\end{array}$ & $\begin{array}{l}\text { Vaccine efficacy (HPV vaccine } \\
\text { type) \% (95\% Cl) }\end{array}$ \\
\hline HPV I6 & $765 / 768$ & $0,2,6$ & 17 & $100(90-100)$ \\
HPV 6/II/16/18 & $277 / 275$ & $0,2,6$ & 35 & $89(70-97)$ \\
HPV 6/II/16/18 & $104 / 120$ & $0,2,6$ & 60 & $95(69-100)$ \\
\hline
\end{tabular}

aKoutsky et al (2002).

bVilla et al (2005).

'Villa et al (2006).

cancers that are from types other than HPV-16 /18 (Schiller and Nardelli-Haefliger, 2006). In addition, this prophylactic vaccine will only be effective for those individuals that have not been exposed to the high-risk HPV types (Hildesheim et al 2007) as the therapeutic potential of the low-risk types vaccine have not been established.

One of the current thoughts that may circumvent the lack of broad cross-protection is the use of the minor capsid protein, L2. Recently several studies have demonstrated that L2-based vaccines have broad cross-neutralizing epitopes and would thus induce cross-protective immunity to different HPV types (Roden et al 2000; de Jong et al 2002; Palmer et al 2006). While L2-based vaccines have broad cross-protection, the neutralizing antibody titres generated are much lower than the current candidate VLP L1-based vaccines. The prophylactic potential of $\mathrm{L} 2$ based vaccines can possibly be increased by L2 codon optimization or generating a L2 peptide-based vaccine. Nevertheless, it is suggested that extensive pre-clinical studies should be conducted to elucidate ways of increasing the immunogenicity of L2-based vaccines.

Table 4 Selected recommendations by ACIP $^{\mathrm{a}}$ for the use of Gardasil ${ }^{\circledR}$ following on from its licensure

\begin{tabular}{ll}
\hline Vaccination program & Recommendations \\
\hline I. Route of administration & $\begin{array}{l}\text { Intramuscular } \\
\text { Three-dose regime } \\
(0,2 \text {, and } 6 \text { months) } \\
\text { b9, } 11-12 \text { yrs }\end{array}$ \\
$\begin{array}{ll}\text { 3. Age of females } \\
\text { at vaccination }\end{array}$ & $\begin{array}{l}\text { (13-26 yrs } \\
\text { 4. Catch-up age at vaccination }\end{array}$ \\
5. Post-vaccination & $\begin{array}{l}\text { screening is compulsory } \\
\text { Not recommended (the efficacy }\end{array}$ \\
6. Vaccination of males & data are not yet available) \\
7. Groups not included in program & Females $>26$ yrs (data not yet \\
& available) \\
& Females $<9$ yrs \\
\hline
\end{tabular}

${ }^{a}$ ACIP - Advisory Committee on Immunization Practices (Markowitz et al 2007).

b It is recommended that females as young as 9 years can be vaccinated.

${ }^{\mathrm{c}}$ These are females that have not been previously vaccinated.

\section{Availability of the quadrivalent vaccine in developing countries}

The cost effectiveness of the current quadrivalent vaccine has been examined using the Markov mathematical model (Sanders and Taira 2003; Goldie et al 2004; Taira et al 2004). This model was used to estimate the cost per quality-adjusted life year (QALY) and deliberate on the impact and cost of HPV vaccination for a given group, without considering the effect of vaccination on HPV transmission in the population (Goldie et al 2004; Markowitz et al 2007). One model estimated that the lifetime risk for cervical cancer in the vaccinated group would be reduced by $58 \%$ and the incidence of cervical cancer would be reduced by $20 \%$ compared with no vaccination (Goldie et al 2004). However, as these models have been estimated for developed countries where vaccination coverage would probably be $70 \%-100 \%$, widespread distribution of the vaccine will not be achieved in developing countries where the vaccines are needed most. Given that the burden of cervical cancer in most developing countries is attributed to poverty, lack of education, lack of effective screening programs, lack of resources (human and financial) and infrastructure (Denny et al 2006), widespread distribution of the vaccine will not be successful. In addition, the vaccines would need proper cold chain for storage as the route of administration is intramuscular making it too expensive to distribute in low-resource settings. It is suggested that funding sources and commercial companies should provide or assist the low-resource communities with financial and perhaps human resources for the distribution of the prophylactic vaccine in conjunction with a routine screening program for cervical disease.

\section{Public health burden in developing countries}

A further significant health problem in developing countries is infection with the human immunodeficiency virus (HIV). In sub-saharan Africa the epidemic has grown exponentially over the past 15 years making it the worst HIV epidemic in 
the world (Department of health of South Africa 2005) and the availability of antiretroviral therapies are limited. In addition, it has been reported that HIV positive women are at an increased risk of developing cervical squamous intraepithelial lesions (SIL) and cervical cancer (La Ruche et al 1998; Sitas et al 2000). Moreover, cervical cancer is included as one of the defining conditions of the acquired immune deficiency syndrome (AIDS) (Centers for Disease Control and Prevention 1993). Thus, this health problem would render a significant portion of the sexual active population immunocompromised and will probably render the quadrivalent vaccine ineffective.

\section{Therapeutic potential of Gardasil}

Recently, in a Phase III community based randomized trial, it has been demonstrated that vaccination with a bivalent HPV-16/18 L1 VLP vaccine did not induce viral clearance in women with existing HPV induced infection (Hildesheim et al 2007). However, there are no placebo-controlled human trials that show the therapeutic benefit of the low-risk HPV types vaccines that have been included in Gardasil. For this HPV VLP L1 vaccine to afford a positive therapeutic effect, a strong cytotoxic T-cell (CTL) response should be elicited. However, given that the important stages in the development of cervical cancer are, integration of the viral genome into the host cell chromosomes and the consistent expression of HPV E6 and E7 proteins in cervical cancer cells, the L1 gene may be disrupted (Roden and $\mathrm{Wu} 2006$ ). Therefore, the low levels of L1 will not induce a L1-specific CTL response and the elimination of established HPV-induced lesions will be not be achieved by the VLP L1 quadrivalent vaccine.

However, as discussed above, L2 based vaccines show promise as a potential candidate for the next generation of prophylactic vaccines. L2 based vaccines have also been tested in a therapeutic setting and have provided encouraging results in the CRPV rabbit challenge model (Govan and Williamson 2007). It was demonstrated that the regression of CRPV-induced papillomas was achieved following immunization of rabbits with recombinant Bacille Calmette-Guerin rBCG expressing CRPVL2 or CRPVL2E7E2 proteins (Govan and Williamson 2007). This L2-based vaccine approach is promising and warrants further preclinical investigations to increase the efficacy of a possible combined prophylactic and therapeutic candidate vaccine.

\section{Conclusion}

The development of the current effective quadrivalent vaccine is a major breakthrough in HPV research. Indeed, the vaccine will serve to significantly reduce the burden of HPV related anogenital infections in young women worldwide. However, it should be clear from this review that this quadrivalent vaccine is not the ideal vaccine for developing countries and fervent basic scientific research need to continue and build on what we already know. For instance, work on L2 needs to continue to potentially provide a broad cross-protection and second generation HPV vaccine. Issues of vaccine availability and cost in the developing countries also need to be addressed with the aim being to reduce the global burden of HPV disease rather than only in countries that can afford vaccines.

\section{References}

Bernard HU. 2005. The clinical importance of the nomenclature, evolution and taxonomy of human papillomaviruses. J Clin Virol, 32S:S1-S6.

Brandsma JL, Shlyankevich M, Zhang L, et al. 2004. Vaccination of rabbits with an adenovirus vector expressing the papillomavirus E2 protein leads to clearance of papillomas and infection. $J$ Virol, 78:116-23.

Breitburd F, Kirnbauer R, Hubbert NL, et al. 1995. Immunization with viruslike particles form cottontail rabbit papillomavirus (CRPV) can protect against experimental CRPV infection. J Virol, 69:3959-63.

Burchell AN, Winer RL, de Sanjose S, et al. 2006 Chapter 6: Epidemiology and transmission dynamics of genital HPV infection. Vaccine, 24 Suppl 3:S52-61.

Centers for Disease Control and Prevention. 1993 revised classification system for HIV infection and expanded surveillance case definition for AIDS among adolescents and adults. JAMA, 269:729-30

Christensen ND, Höpfl R, DiAngelo SL, et al. 1994. Assembled baculovirusexpressed human papillomavirus type $11 \mathrm{~L} 1$ capsid protein virus-like particles are recognized by neutralizing monoclonal antibodies and induce high titres of neutralizing antibodies. J Gen Virol, 75:2271-76.

de Jong A, O'Neill T, Khan AY, et al. 2002. Enhancement of human papillomavirus (HPV) type 16 E6 and E7-specific T-cell immunity in healthy volunteers through vaccination with TA-CIN, an HPV16 L2E7E6 fusion protein vaccine. Vaccine, 20: 3456-64.

de Villiers EM, Fauquet C, Broker TR, et al. 2004. Classification of papillomaviruses. Virology, 324:17-27.

Denny L, Quinn M, and Sankaranarayanan R. 2006. Chapter 8: Screening for cervical cancer in developing countries. Vaccine, 24(Suppl 3):S71-7.

Department of Health of South Africa. 2005. National HIV and syphilis antenatal sero-prevalence survey in South Africa, 2004. Pretoria.

Deshpande, A. Nolan JP, White PS, et al. 2005. TNF-a promoter polymorphisms and susceptibility to human papillomavirus 16-associated cervical cancer. J Infect Dis, 191:969-76.

Ferlay J, Bray F, Pisani P. 2004. Cancer Incidence, Mortality and Prevalence Worlwide. IARC CancerBase No. 5 version 2.0. Lyon: IARCCPress.

Frazer I. 2004. Prevention of cervical cancer through papillomavirus vaccination. Nature Reviews Immunol, 4:46-54.

Garland SM, Hernandez-Avila M, Wheeler CM, et al. 2007. Quadrivalent vaccine against human papillomavirus to prevent anogenital diseases. N Engl J Med, 356:1991-3.

Goldie SJ, Kohli M, Grima D, et al. 2004. Projected clinical benefits and cost-effectiveness of a human papillomavirus $16 / 18$ vaccine. $J$ Natl Cancer Inst, 96:604-15.

Govan VA, Carrara HR, Sachs JA, et al. 2003. Ethnic differences in allelic distribution of IFN-g in South African women but no link with cervical cancer. $J$ Carcinogenesis, 2:3

Govan VA, Christensen ND, Berkower C, et al. 2006. Immunisation with recombinant $\mathrm{BCG}$ expressing the cottontail rabbit papillomavirus (CRPV) L1 gene provides protection from CRPV challenge. Vaccine, 24:2087-93. 
Govan VA, Constant D, Hoffman M, et al. 2005. The allelic distribution of -308 Tumor Necrosis Factor-alpha gene polymorphism in South African women with cervical cancer and control women. $B M C$ Cancer, 6:24

Govan VA, Williamson AL. 2007. Rabbits immunised with recombinant BCG expressing the cottontail rabbit papillomavirus (CRPV) L2E7E2 genes induces regression of established papillomas. Virus Res, 127:43-8.

Harper DM, Franco EL, Wheeler CM, et al. 2006. Sustained efficacy up to 4.5 years of a bivalent L1 virus-like particle vaccine against human papillomavirus types 16 and 18: follow-up from a randomised control trial. Lancet, 367:1247-55.

Hildesheim A, Herrero R, Wacholder S, et al. 2007. Effect of Human Papillomavirus 16/18 L1 virus-like particle vaccine among young women with pre-existing infection. JAMA, 298:743-53.

Hines J. F. Ghim SJ, Christensen ND, et al. 1994. The expression of L1proteins of HPV-1, HPV-6, and HPV-11 display type-specific epitopes with native conformation and reactivity with neutralizing and non-neutralizing antibodies. Pathobiology, 62:165-71.

Jansen KU, Rosolowsky M, Schultz LD, et al. 1995. Vaccination with yeast-expressed cottontail rabbit papillomavirus (CRPV) virus-like particles protects rabbits from CRPV-induced papilloma formation. Vaccine, 13:1509-14

Koutsky LA. 1997. Epidemiology of genital human papillomavirus infection. Am J Med, 102:3-8.

Koutsky LA, Ault KA, Wheeler CM, et al. 2002. Proof of Principle Study Investigators. A controlled trial of a human papillomavirus type16 vaccine. $N$ Engl J Med, 347:1645-51.

La Ruche G, You B, Mensah-Ado I, et al. 1998. Human Papillomavirus and Human Immunodeficiency Virus Infections: Relation with cervical dysplasia-neoplasia in African Women. Int J Cancer, 76:480-6.

Magnusson PKE, Gyllensten U. 2000. Cervical cancer risk: is there a genetic component? Mol Med Today, 6:145-48.

Markowitz LE, Dunne EF, Saraiya M, et al. 2007. Centers for Disease Control and Prevention (CDC); Advisory Committee on Immunization Practices (ACIP). Quadrivalent Human Papillomavirus Vaccine: Recommendations of the Advisory Committee on Immunization Practices (ACIP). MMWR Recomm Rep, 56(RR-2):1-24.

Munoz N, Bosch FX, de Sanjose S, et al. 2003. International Agency for Research on Cancer Multicenter Cervical Cancer Study Group Epidemiologic classification of human papillomavirus types associated with cervical cancer. $N$ Engl J Med, 348:518-27.
Palmer KE, Benko A, Doucette SA, et al. 2006. Protection of rabbits against cutaneous papillomavirus infection using recombinant tobacco mosaic virus containing L2 capsid epitopes. Vaccine, 24:5516-25.

Robinson W. 3rd. 2001. Management of cervical cancer neoplasia. Cancer Treat Res, 104:287-302.

Roden RB, Yutzy WH 4th, Fallon R, et al. 2000. Minor capsid protein of human genital papillomaviruses contains subdominant, crossneutralizing epitopes. Virology, 270: 254-7.

Roden R, Wu TC. 2006. How will HPV vaccines affect cervical cancer? Nat Rev Cancer, 6:753-63.

Sanders GD, Taira AV. 2003. Cost-effectiveness of a potential vaccine for human papillomavirus. Emerg Infect Dis, 9:37-48.

Schiller JT, Nardelli-Haefliger D. 2006. Chapter 17: Second generation HPV vaccines to prevent cervical cancer. Vaccine, (Suppl 3):S147-53.

Sitas F, Pacella-Norman R, Carrara H, 2000. The spectrum of HIV-1 related cancers in South Africa. Int J Cancer, 88:489-92.

Stanczuk GA, Sibanda EN, Perrey C, et al. 2001. Cancer of the uterine cervix may be significantly associated with a gene polymorphism coding for increased IL-10 production. Int J Cancer, 94:792-94.

Stanley M. 2003. Immune intervention in HPV infections: current progress and future developments. Expert Rev Vaccines. 2:615-7.

Taira AV, Neukermans CP, Sanders GD. 2004. Evaluating human papillomavirus vaccination programs. Emerg Infect Dis, 10:1915-23.

Villa LL, Costa RL, Petta CA, et al. 2005. Prophylactic quadrivalent human papillomavirus (types $6,11,16$, and 18) L1 virus-like particle vaccine in young women: a randomised double-blind placebo-controlled multicentre phase II efficacy trial. Lancet Oncol, 6:271-8.

Villa LL, Costa RL, Petta CA, et al. 2006. High sustained efficacy of a prophylactic quadrivalent human papillomavirus types 6/11/16/18 L1 virus-like particle vaccine through 5 years of follow-up. Br J Cancer, 95:1459-66.

[WHO] World Health Organization. 2004. Vaccines against human papillomavirus [online]. Accessed July 12, 2004. URL: http://www.who. int/vaccines/en/hpvrd.shtml/shtml.

zur Hausen, H. 2000. Papillomaviruses causing cancer: evasion from host-cell host in early events in carcinogenesis. J Natl. Cancer Inst, 92:690-8. 